\title{
Association of headache with childhood adversity and mental disorder: cross-national study
}

Sing Lee, Adley Tsang, Michael Von Korff, Ron de Graaf, Corina Benjet, Josep Maria Haro, Matthias Angermeyer, Koen Demyttenaere, Giovanni de Girolamo, Isabelle Gasquet, Kathleen Merikangas, José Posada-Villa, Tadashi Takeshima and Ronald C. Kessler

\section{Background}

Community studies about the association of headache with both childhood family adversities and depression/anxiety disorders are limited.

\section{Aims \\ To assess the independent and joint associations of childhood family adversities and early-onset depression and anxiety disorders with risks of adult-onset headache.}

\section{Method}

Data were pooled from cross-sectional community surveys conducted in ten Latin and North American, European and Asian countries ( $n=18303)$ by using standardised instruments. Headache and a range of childhood family adversities were assessed by self-report.

\section{Results}

The number of childhood family adversities was associated with adult-onset headache after adjusting for gender, age, country and early-onset depression/anxiety disorder status (for one adversity, hazard ratio (HR)=1.22-1.6; for two adversities, $H R=1.19-1.67$; for three or more adversities, $H R=1.37-1.95$ ). Early and current onset of depression/anxiety disorders were independently associated ( $H R=1.42-1.89)$ with adult-onset headache after controlling for number of childhood family adversities.

\section{Conclusions}

The findings call for a broad developmental perspective concerning risk factors for development of headache.

\section{Declaration of interest}

None. Funding detailed in Acknowledgements.
Headache has been consistently shown to be associated with depression and anxiety disorders according to both community and clinical studies. ${ }^{1-3}$ The exact nature of this association is unclear because both headache and mental disorders are heterogeneous and may share common risk factors. Although the association of life stressors with both headache and mental disorders is well established, relatively few studies have examined these associations from a socio-developmental perspective.

Recent studies have found that adverse childhood events may play a role in the association between headache and mental disorders among adults. ${ }^{4,5}$ However, most of these studies involved clinical rather than representative community samples. They also focused on depression rather than anxiety disorders and usually assessed mental disorder status by self-rated scales rather than standardised diagnostic interview. ${ }^{6,7}$ Moreover, although mental disorders and childhood family adversities are prevalent in lowand middle-income countries, most research has been conducted in high-income countries. ${ }^{4,5}$

The present study assesses the independent and joint effects of significant childhood family adversities and early-onset depression and anxiety disorders in influencing risks of developing adultonset headache. This assessment is based on cross-national data pooled from community-based surveys conducted in 10 countries that participated in the World Mental Health Survey Consortium (www.hcp.med.harvard.edu/wmh).

\section{Method}

\section{Samples}

Ten surveys were carried out in the Americas (Colombia, Mexico, USA), Europe (Belgium, France, Germany, Italy, The Netherlands, Spain), and Asia (Japan). All surveys were based on multistage, clustered, area probability household samples. Interviews were carried out face to face by trained lay interviewers. Sample sizes ranged from 2372 (Netherlands) to 9282 (USA). Response rates ranged from $45.9 \%$ (France) to $87.7 \%$ (Colombia), with an average response rate of $70.8 \%$.

Internal subsampling was used to reduce respondent burden and cost by dividing the interview into two parts. Part 1 included the core diagnostic assessment of mental disorders. Part 2 included additional information relevant to a wide range of survey objectives, including assessment of chronic physical conditions and childhood family adversities. All respondents completed part 1. All part 1 respondents who met criteria for any mental disorder and a probability sample of other respondents were administered part 2. Part 2 respondents were weighted by the inverse of their probability of selection for part 2 of the interview to adjust for differential sampling. Analyses in this paper were based on the weighted part 2 subsample $(n=18303)$. Additional weights were used to adjust for differential probabilities of selection within households, adjust for non-response, and match the samples to population socio-demographic distributions.

\section{Mental disorder status}

All surveys used the World Mental Health (WMH) Survey version of the World Health Organization's Composite International Diagnostic Interview (WHO-CIDI) ${ }^{8}$ (WMH-CIDI; current version, CIDI 3.0), a fully structured diagnostic interview, to assess disorders and treatment. Methodological evidence collected in the WHO-CIDI field trials and later clinical calibration studies showed that all the disorders considered herein were assessed with acceptable reliability and validity in the original CIDI, ${ }^{9}$ and the WMH-CIDI. ${ }^{10}$ Disorders were assessed using the definitions and criteria of the DSM-IV. ${ }^{11}$ Composite International Diagnostic Interview organic exclusion rules were imposed (i.e. the diagnosis 
was not made if the respondent indicated that the episode of depression or anxiety symptoms was due to physical illness or injury or use of medication, drugs or alcohol).

This paper includes anxiety disorders (generalised anxiety disorder, panic disorder and/or agoraphobia, post-traumatic stress disorder and social phobia) and major depressive episode, which occurred in the previous 12 months and before age 21 years. Depression and anxiety disorders were aggregated into a single category, on the basis of prior findings from the WMH surveys that anxiety disorders and major depression have independent associations of a comparable magnitude with headache and with other chronic physical conditions.

\section{Headache}

Severe headache was ascertained as part of a chronic physical disorder checklist, of the kind commonly used in national health surveys. ${ }^{12}$ Respondents were asked whether they had ever had frequent or severe headache in the previous 12 months. Prior research has demonstrated reasonable correspondence between self-reported chronic conditions (e.g. diabetes, heart disease and headache) and records of general practitioners, ${ }^{13}$ but lifetime history of severe headache is subject to recall bias. Although we assessed whether recall bias associated with current depression or anxiety disorder influenced the association of childhood family adversities with adult onset of frequent or severe headaches, the problem of retrospective recall may admittedly remain.

\section{Childhood family adversities}

The following kinds of childhood family adversities were included in the present study: physical abuse, sexual abuse, neglect, parental death, parental divorce, other parental loss, parental mental disorder, parental substance misuse, parental criminal behaviour, family violence and family economic adversity. Those respondents who met the criteria specified for a given adversity before the age of 18 years were coded as having experienced childhood family adversity (online Appendix DS1).

\section{Training and field procedures}

Experienced CIDI trainers in the USA trained bilingual supervisors in each country. The WHO translation protocol was used to translate instruments and training materials. Some surveys were carried out in bilingual form (Belgium). Other surveys were carried out exclusively in the country's official language. Persons who could not speak these languages were excluded. Quality control protocols, described in more detail elsewhere, ${ }^{14}$ were standardised across countries to check on interviewer accuracy and to specify data cleaning and coding procedures. The institutional review board of the organisation that coordinated the survey in each country approved and monitored compliance with procedures for obtaining informed consent and protecting participants.

\section{Statistical analysis}

The association of childhood family adversities and early-onset mental disorders with adult-onset frequent or severe headache was studied with discrete-time survival analyses, using retrospectively reported age at onset of headache (reported in whole years). The start of the period at risk of adult-onset headache was set at age 21 years. Persons who reported that frequent or severe headache developed before age 21 were excluded.

Cox proportional hazards models were constructed to estimate risk of adult-onset headache as a function of number and type of childhood family adversities and early-onset depression/anxiety disorder status while adjusting for potential confounders (gender, current age and smoking). Country was included in the analyses as a stratifying variable, which allowed each country to have a unique hazard function. This was necessary because of large differences in prevalence rates of childhood family adversities, mental disorders and chronic physical disorders between countries, and to allow for the slight differences in measurement of childhood family adversities among countries (e.g. data from European countries did not include childhood neglect or parental divorce).

In the Cox proportional hazard regression analyses, time to age at onset of headache from age 20 was the dependent variable. Persons who had not developed headache were censored at their current age. The associations are expressed as hazard ratios measuring relative risk. Childhood family adversities were analysed in four categories of number of adversities (none, 1, 2, $3+$ ), with no adversities as the reference group. Childhood family adversities and early-onset mental disorders were included in the models both separately and simultaneously.

To account for the possibility of differential recall of childhood family adversities among those with a current depressive or anxiety disorder, we performed an additional analysis that adjusted for current (12-month) depression or anxiety disorder. We also performed an additional analysis adjusting for educational attainment. Because the inclusion of education in the models made virtually no difference in results, we report results unadjusted for education (detailed information on education was not collected in France, so to have reported all results adjusted for education would also have meant excluding France from analysis). We screened for interaction of childhood family adversities with early-onset depression/anxiety disorder in predicting headache onset, but the interaction was non-significant so only main effects are reported in this paper.

Ninety-five per cent confidence intervals were calculated for all hazard ratios. Statistical significance level was set at 0.05 for a twosided test. The analyses were performed using the SURVIVAL procedure in SUDAAN (version 9.0.1, SAS-Windows). statistical software to account for the complex sample design. In all multivariate models, a complete-case approach was used, but the WMH survey used multiple imputation methods to impute missing values for the childhood family adversities. The survival analyses employed sample weights to adjust for differences in probability of selection. The unadjusted cumulative percentage with adult onset of frequent or severe headache by age for persons with $v$. without early-onset depression/anxiety disorder, and for persons with 0,1 or $2+$ childhood family adversities were graphed with product-limit (Kaplan-Meier) life-table estimates developed using SAS PROC LIFETEST (version 9.1.3, Windows).

\section{Results}

Overall, $11.3 \%$ of the population had headache and $9.1 \%$ had early-onset depression/anxiety disorder. Childhood family adversities were common (43.2\%) (Table 1). The prevalence of frequent or severe headache varied; the lowest rate was in Japan $(5.9 \%)$ and the highest rate was in Colombia (17.5\%). Early-onset mental disorder was most common in the USA (17.3\%) and least common in Japan $(2.2 \%)$. Childhood family adversities were most common in Colombia (64.5\%) and least common in Spain (28.5\%). Among the different types of childhood family adversities, parental death during childhood was generally the most common form (12.9\% of the study population experienced this adversity in childhood). 


\begin{tabular}{|c|c|c|c|c|c|}
\hline Country & $\begin{array}{c}\text { Sample size } \\
n\end{array}$ & $\begin{array}{l}\text { Age, years } \\
\text { Mean (s.d.) }\end{array}$ & $\begin{array}{c}\text { Headache } \\
\%\end{array}$ & $\begin{array}{l}\text { Any childhood family } \\
\text { adversities }^{\text {a }} \\
\%\end{array}$ & $\begin{array}{l}\text { Early onset of any } \\
\text { depression/anxiety } \\
\text { disorders, }{ }^{\text {b } \%}\end{array}$ \\
\hline Belgium & 916 & $48.8(16.81)$ & 9.5 & 32.9 & 5.2 \\
\hline Colombia & 1790 & $39.2(12.25)$ & 17.5 & 64.5 & 9.0 \\
\hline France & 1172 & $48.3(16.74)$ & 11.9 & 39.8 & 10.0 \\
\hline Germany & 1150 & $49.1(17.65)$ & 9.9 & 31.2 & 4.6 \\
\hline Italy & 1502 & $48.9(17.71)$ & 7.5 & 28.8 & 4.2 \\
\hline Japan & 820 & $52.6(17.79)$ & 5.9 & 34.1 & 2.2 \\
\hline Mexico & 1893 & $37.9(12.19)$ & 11.0 & 53.7 & 5.7 \\
\hline The Netherlands & 945 & $47.3(16.04)$ & 9.9 & 37.5 & 7.2 \\
\hline Spain & 1817 & $47.2(18.07)$ & 8.4 & 28.5 & 3.7 \\
\hline US & 4550 & $47.9(17.29)$ & 13.1 & 49.3 & 17.3 \\
\hline Total & 16555 & $46.2(16.9)$ & 11.3 & 43.2 & 9.1 \\
\hline \multicolumn{6}{|c|}{$\begin{array}{l}\text { a. Childhood family adversities included neglect, physical abuse, sexual abuse, parental death, parental divorce, other loss of parent during childhood, family economic adversity, } \\
\text { violence in family, criminal behaviour in family, parental mental disorder and substance use disorder. } \\
\text { b. Assessed early-onset (before age } 21 \text { years) disorders include major depressive episode, generalised anxiety disorder, post-traumatic stress disorder, social phobia, panic disorde } \\
\text { and agoraphobia. }\end{array}$} \\
\hline
\end{tabular}

In the proportional hazard analyses of the association of number of childhood family adversities with headache, a linear relationship was found. That is, those with three or more types of childhood family adversities were at higher risk of adult-onset headache than those with one or two adversities (Table 2, model A). This was true for the analysis controlling for depression/ anxiety disorders present in the previous year (Table 2, model B) as well as for the analysis controlling for onset of depression/ anxiety disorders before age 21 (Table 2, model C). Early-onset depression/anxiety disorders were also associated with increased risk of adult-onset headache after controlling for the number of childhood family adversities. Female gender and higher age were associated with increased risk of adult-onset headache in all models.

When each childhood adversity was considered independently in separate models controlling for gender and age (with stratification by country), we found that sexual abuse, physical abuse, parental mental and substance use disorders, criminal behaviour and violence in the family, and other loss of parents during childhood were significantly associated with adult-onset headache, whereas parental death, divorce and economic adversity during childhood were not (Table 3). Using the same methods of analysis, each of the early-onset depression/anxiety disorders was considered in a separate model. Each disorder was found to be associated with headache, including panic disorder/agoraphobia, major depressive episode, generalised anxiety disorder, post-traumatic stress disorder and social phobia.

We assessed the interaction of early-onset depression/ anxiety disorders and having one or more childhood family adversities, adjusting for gender and age with stratification by country. The interaction of childhood adversity and early-onset depression/ anxiety disorders was non-significant (results not shown), so there was no evidence of a synergistic effect of childhood adversity and early-onset mental disorder on risks of adult-onset headache.

Figure 1 shows the cumulative percentage by age for adultonset headache among respondents with early-onset depression/ anxiety disorders $v$. those without. Both curves were steeper for early adulthood as more than half of adult-onset headaches occurred between ages 21 and 40. The rate of increase and cumulative occurrence of headache were greater for those with early-onset depression/anxiety disorders than those without. As shown in Fig. 2, increase in the number of childhood family adversities was also associated with increase in the cumulative occurrence of headache. The rate of increase was similar initially for those with any number of adversities, but for those who had had more childhood family adversities it increased at a higher rate from age 30 onwards. Thus, as the respondents aged, the presence of multiple childhood family adversities was associated with a greater likelihood of headache onset.

\begin{tabular}{|c|c|c|c|}
\hline Risk factor & Model A, HR $(95 \% \mathrm{Cl})$ & Model B, HR (95\%Cl) & Model C, HR (95\%Cl) \\
\hline \multicolumn{4}{|l|}{ Number of childhood family adversities } \\
\hline One & $1.43(1.24-1.64)$ & $1.39(1.21-1.59)$ & $1.40(1.22-1.60)$ \\
\hline Two & $1.47(1.24-1.75)$ & $1.38(1.17-1.64)$ & $1.41(1.19-1.67)$ \\
\hline Three or more & $1.80(1.52-2.13)$ & $1.52(1.28-1.81)$ & $1.63(1.37-1.95)$ \\
\hline \multicolumn{2}{|l|}{ Previous year depression/anxiety disorders } & $2.16(1.92-2.44)$ & \\
\hline \multicolumn{3}{|l|}{ Early-onset depression/anxiety disorders } & $1.64(1.42-1.89)$ \\
\hline Female gender & $2.16(1.91-2.44)$ & $2.07(1.83-2.44)$ & $2.11(1.87-2.39)$ \\
\hline Age, years & $0.95(0.94-0.95)$ & $0.95(0.94-0.96)$ & $0.95(0.94-0.95)$ \\
\hline \multicolumn{4}{|c|}{$\begin{array}{l}\text { a. Hazard ratios estimated by Cox regression proportional hazards model based on age at onset of headache. Analyses carried out with SUDAAN survival procedure accounting } \\
\text { for complex sample design. Country was entered as a stratification variable which permits the hazard functions to differ for each country. Persons with physical disorder onset prior } \\
\text { to age } 21 \text { years are excluded. } \\
\text { b. Gender and age stratified by country (model A) with additional predictors: depression/anxiety disorders in previous year (model B) and early onset of depression/anxiety disorders } \\
\text { (model C). }\end{array}$} \\
\hline
\end{tabular}




\begin{tabular}{|c|c|c|}
\hline Risk factors & Hazard ratios & $95 \% \mathrm{Cl}$ \\
\hline \multicolumn{3}{|l|}{ Childhood family adversities } \\
\hline Sexual abuse & $1.73^{* * *}$ & $1.38-2.17$ \\
\hline Physical abuse & $1.64^{* * *}$ & $1.44-1.88$ \\
\hline Parental mental disorder & $1.52^{\star \star \star *}$ & $1.25-1.83$ \\
\hline Family violence & $1.51^{* * *}$ & $1.30-1.76$ \\
\hline Criminal behaviour in family & $1.44^{* *}$ & $1.10-1.18$ \\
\hline Parental substance use disorder & $1.42^{\star * *}$ & $1.18-1.71$ \\
\hline Other loss of parent during childhood & $1.29 *$ & $1.06-1.58$ \\
\hline Neglect $^{\mathrm{C}}$ & $1.21 *$ & $1.02-1.43$ \\
\hline Economic adversity & 1.21 & $0.98-1.48$ \\
\hline Parental death & 1.10 & $0.93-1.31$ \\
\hline Parental divorce ${ }^{c}$ & 1.01 & $0.84-1.22$ \\
\hline \multicolumn{3}{|l|}{ Depression/anxiety disorders } \\
\hline Panic/agoraphobia & $1.76^{* * *}$ & $1.37-2.25$ \\
\hline Major depressive episode & $1.68^{* * *}$ & $1.40-2.03$ \\
\hline Generalised anxiety disorder & $1.65^{\star \star \star *}$ & $1.32-2.06$ \\
\hline Post-traumatic stress disorder & $1.65^{\star *}$ & $1.19-2.30$ \\
\hline Social phobia & $1.61^{\star \star \star}$ & $1.35-1.91$ \\
\hline
\end{tabular}

a. Hazard ratios estimated by one Cox regression proportional hazards model for each adversity predictor/each depression/anxiety disorder based on age at onset of headache. Analyses carried out with SUDAAN survival procedure accounting for headache. Analyses carried out with SUDAAN survival procedure accounting
complex sample design. Country was entered as a stratification variable which complex sample design. Country was entered as a stratification variable which
permits the hazard functions to differ for each country. Persons with physical permits the hazard functions to differ for each country.
disorder onset prior to age 21 years are excluded.

disorder onset prior to age 21 years are excluded.
b. Adjusted for age and gender, analyses stratified by country.

b. Adjusted for age and gender, analyses stratified by country.
c. Belgium, France, Germany, The Netherlands, Italy, Spain (ESEMED) did not ask C. Belgium, France, Germany, The Netherlands, Italy, Spain (ESEMED) did not ask
about childhood neglect or parental divorce, but it was possible to impute parental divorce.

${ }^{*} P<0.05 ;{ }^{* * P}<0.01 ; * * * P<0.001$

\section{Discussion}

\section{Types of association}

Because of evidence of clustering of childhood adversities in previous studies of the association between such adversities and mental disorders, ${ }^{15}$ we assessed a broad range of childhood family adversities in our study. Early-onset mental disorders and childhood family adversities were independently associated with adult-onset frequent or severe headache. This association was strongest for persons with three or more childhood family adversities. This finding is the first of its kind to show in a large cross-national community sample that the association between childhood family adversities and adult onset of headache is

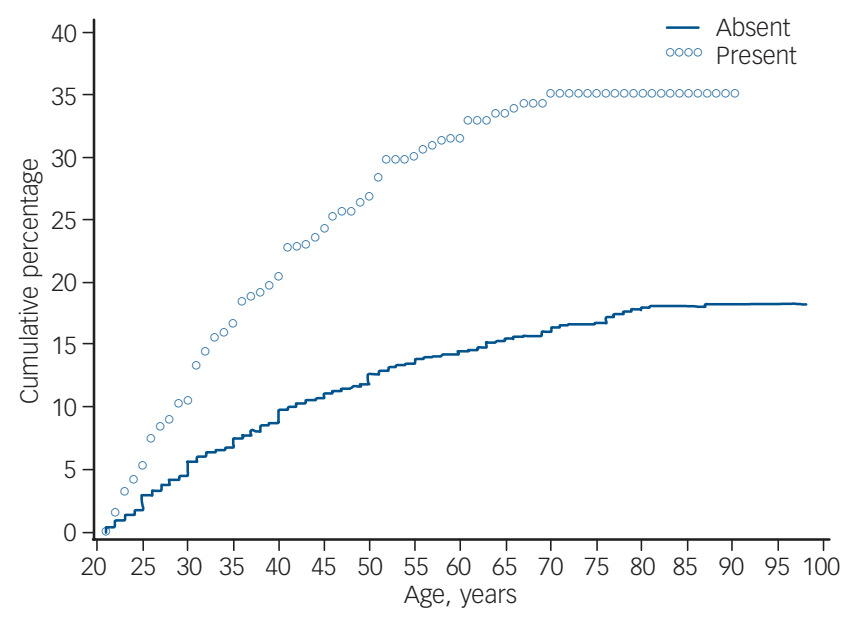

Fig. 1 Kaplan-Meier curve for adult-onset headache by age for persons with $v$. without early-onset depression/anxiety disorders.

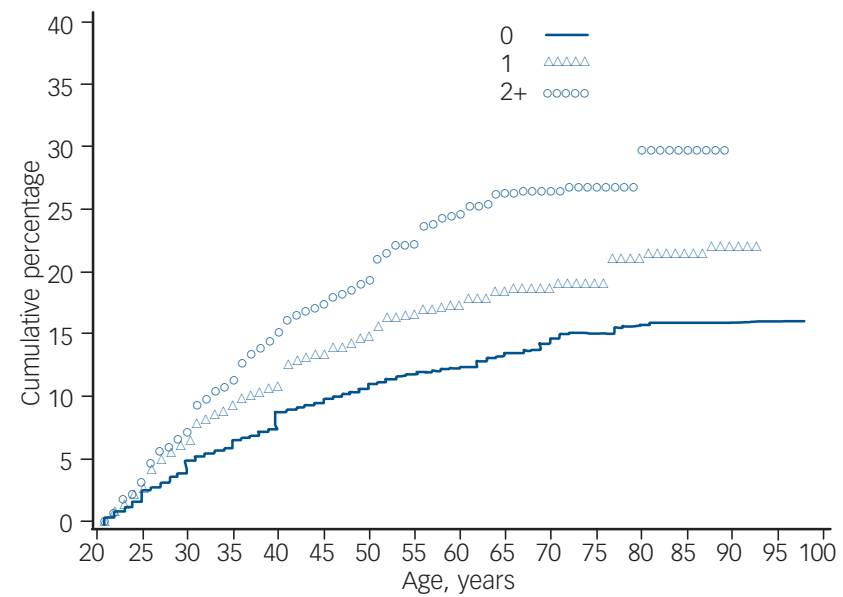

Fig. 2 Kaplan-Meier curve for the cumulative percentage with adult-onset headache by age for persons with none, one, and two or more childhood family adversities.

independent of mental disorders. Although mental disorder was still independently associated with headache, distinct associations of both types of predictors with headache have not been demonstrated in previous studies. ${ }^{4,5}$

In our analyses that decomposed the association of specific childhood family adversities with headache risks, not all the childhood family adversities were found to predict increased risk. Sexual and physical abuse, parental mental and substance disorders and family antisocial behaviours showed the most robust associations with risk of adult-onset headache. Parental death, divorce, and economic adversity were not significantly related. This is different from a previous case-control study, which found significant associations between migraine and parental divorce and chronic financial difficulties in the family after adjustment for education, self-reported general physical health, and depression. ${ }^{5}$

Sexual abuse and physical abuse have been the most frequently studied childhood family adversities in relation to adult headache disorders. Our study confirmed previous research showing an association between childhood abuse and headache. ${ }^{16,17}$ Additionally, the association remained significant when early-onset mental disorders were included in the analysis. This is in keeping with studies showing that headache was associated with childhood family adversities after controlling for depression ${ }^{7}$ and mental disorders in general. ${ }^{18}$

\section{Limitations}

Our study has several significant limitations relevant to interpretation of its results. Although we used age-at-onset data for childhood family adversities and adult-onset headache to assess temporal ordering, the cross-sectional methodology used imposed a significant shortcoming. Since lifetime history of frequent or severe headache and of childhood family adversities were both ascertained by retrospective self-report, there were multiple opportunities for recall bias to affect both in a similar fashion, thereby introducing spurious correlation. We sought to control this potential bias by carrying out an analysis which controlled for current depression and anxiety disorder. This analysis yielded similar results to analyses which did not control for current mental disorder. None the less, the potential for recall bias to influence the results reported here cannot be excluded, especially for childhood family adversities. Although a 
comprehensive review indicates that adult retrospective reports of adverse childhood experiences have a worthwhile place in research, substantial false negatives and measurement errors remain possible. ${ }^{19}$ Prospective research that encompasses corroborative tools of assessment of childhood adversities is needed to address this methodological weakness of our study. We also have not tackled the potentially different meaning and impact of childhood adversity across the participating countries. Parental divorce, for example, may exert dissimilar impact on individuals who grow up in countries with different social and religious attitudes towards broken families. Likewise, the impact of family economic adversity or parental death may vary according to the quality of social service available in a country. These and other cultural differences need to be examined in future country-specific analyses that take social context into account. Regarding the assessment of headache, it was based on a question about history of frequent or severe headache, so that information about the subtypes, chronicity and frequency of attacks of headache was lacking. Consequently, our findings may not be readily compared with research that focused on specific types of headache, especially migraine, which may differ from other kinds of chronic headache in aetiology and the association with depression and childhood family adversities. ${ }^{1,20}$

\section{A broad developmental perspective}

Recognising the limitations of this research, our results suggest that childhood family adversities may predispose individuals to adult-onset headache via mechanisms in addition to Axis I psychopathology. Prior research has found that inadequate coping style and maladaptive personality factors are observed among people who have experienced childhood family adversities. ${ }^{21-23}$ Neuroimaging studies indicate that the brain areas activated during distress caused by social adversities such as exclusion are also activated during physical pain. ${ }^{24}$ However, it should be noted that our analyses did not identify interaction or synergistic effects of the number of childhood family adversities with the presence of early-onset depression/anxiety disorder.

In summary, this research found that the association of risk of developing headache was independently associated with both number of childhood family adversities and the presence of early-onset depression/anxiety disorder. Although the aetiology of headache remains poorly understood, these results suggest that a broad developmental perspective concerning risk factors for development of severe or frequent headache may be needed to understand how life stressors influence risks in combination with depression and anxiety disorders.

Sing Lee, MBBS, FRCPsych, Department of Psychiatry, The Chinese University of Hong Kong, Hong Kong; Adley Tsang, BSOSC, Hong Kong Mood Disorders Center, The Chinese University of Hong Kong, Hong Kong; Michael Von Korff, SCD, Center for Health Studies, Group Health Cooperative, Washington, USA; Ron de Graaf, PhD, Netherlands Institute of Mental Health and Addiction, Utrecht, The Netherlands; Corina Benjet, PhD, National Institute of Psychiatry Ramón de la Fuente, Mexico; Josep Maria Haro, MD, MPH, PhD, Sant Joan de Deu-SSM, de la Fuente, Mexico; Josep Maria Haro, MD, MPH, PhD, Sant Joan de Deu-SSM,
Barcelona, Spain; Matthias Angermeyer, MD, PhD, Center for Public Mental Health, Austria; Koen Demyttenaere, MD, PhD, Department of Neurosciences and Psychiatry, University Hospitals Gasthuisberg, Belgium; Giovanni de Girolamo, MD, Regional Health Care Agency, Emilia-Romagna Region, Bologna, Italy; Isabelle Gasquet, MD, Hôpitaux de Paris, Paris, France, Mission Performance et Prospective Médicales (Direction de la Politique Médicale, AP-HP), France; Kathleen Merikangas, PhD, National Institute of Mental Health, Bethesda, Maryland, USA; José Posada-Villa, MD, Colegio Mayor de Cundinamarca University, Colombia; José Posada-Villa, MD, Colegio Mayor de Cundinamarca University, Colombia;
Tadashi Takeshima, MD, National Institute of Mental Health, National Center of Neurology and Psychiatry, Japan; Ronald C. Kessler, PhD, Department of Health Care Policy, Harvard Medical School, Massachusetts, USA

Correspondence: Professor Sing Lee, Director, Hong Kong Mood Disorders Center, 7A, Block E, Staff Quarters, Prince of Wales Hospital, Shatin, New Territories, Hong Kong. Email: singlee@cuhk.edu.hk

First received 6 Mar 2008, final revision 20 Jun 2008, accepted 22 Jul 2008

\section{Acknowledgements}

The surveys discussed in this article were carried out in conjunction with the World Health Organization World Mental Health (WMH) Survey Initiative. We thank the WMH staff for assistance with instrumentation, fieldwork, and data analysis. These activities were supported by the US National Institute of Mental Health (R01-MH070884), the John D. and Catherine T. MacArthur Foundation, the Pfizer Foundation, the US Public Health Service (R13-MH066849, R01-MH069864 and R01-DA016558), the Fogarty International Center (FIRCA R01-TW006481), the Pan American Health Organization, Eli Lilly \& Co, Ortho-McNeil Pharmaceutical Inc, GlaxoSmithKline, and Bristol-Myers Squibb. A complete list of WMH publications can be found at www.hcp.med.harvard.edu/wmh/. The Colombian National Study of Mental Health is supported by the Ministry of Social Protection. The ESEMeD project is funded by the European Commission (Contracts QLG5-1999-01042; SANCO 2004123); the Piedmont Region (Italy); Fondo de Investigación Sanitaria, Instituto de Salud Carlos III, Spain (FIS 00/0028); Ministerio de Ciencia y Tecnología, Spain (SAF 2000-158-CE); Departament de Salut, Generalitat de Catalunya, Spain (CIBER CB06/02/ 0046, RETICS RD06/0011 REM-TAP); other local agencies; and by an unrestricted educational grant from GlaxoSmithKline. The World Mental Health Japan Survey is supported by the Grant for Research on Psychiatric and Neurological Diseases and Mental Health (H13-SHOGAl-023, H14-TOKUBETSU-026, H16-KOKORO-013) from the Japan Ministry of Health, Labour and Welfare. The Mexican National Comorbidity Survey is supported by
the National Institute of Psychiatry Ramon de la Fuente (INPRFMDIES 4280) and by the National Council on Science and Technology (CONACyT-G30544-H), with supplemental support from the Pan American Health Organization. The US National Comorbidity Survey Replication is supported by the National Institute of Mental Health (U01-MH60220) with supplemental support from the National Institute of Drug Abuse, the Substance Abuse and Mental Health Services Administration, the Robert Wood Johnson Foundation (Grant 044708), and the John W. Alden Trust.

\section{References}

1 Breslau N, Lipton RB, Steward WF, Schultz LR, Welch KM. Comorbidity of migraine and depression: investigating potential etiology and prognosis. Neurology 2003; 60: 1308-12.

2 Radat F, Swendsen J. Psychiatric comorbidity in migraine: a review. Cephalalgia 2005; 25: 165-78.

3 Breslau N, Schultz LR, Steward WF, Lipton RB, Lucia VC, Welch KM. Headache and major depression: is the association specific to migraine? Neurology 2000; 54: 308-13.

4 Tietjen GE, Brandes JL, Digre KB, Baggaley S, Martin VT, Recober A, et al. History of childhood maltreatment is associated with comorbid depression in women with migraine. Neurology 2007; 69: 959-68.

5 Sachs-Ericsson N, Kendall-Tackett K, Hernandez A. Childhood abuse, chronic pain, and depression in the National Comorbidity Survey. Child Abuse Negl 2007; 31: 534-47.

6 Demyttenaere K, Bruffaerts R, Posada-Villa J, Gasquet I, Kovess V, Lepine JP, et al. Prevalence, severity, and unmet need for treatment of mental disorders in the World Health Organization World Mental Health Surveys. JAMA 2004; 291: 2581-90.

7 Scott KM, Bruffaerts R, Tsang A, Ormel J, Alonso J, Angermeyer MC, et al. Depression-anxiety relationships with chronic physical conditions. Results from the World Mental Health surveys. J Affect Disord 2007; 103: 113-20.

8 Kessler RC, Ustun B. The World Mental Health (WMH) Survey Initiative version of the World Health Organization (WHO) Composite International Diagnostic Interview (CIDI). Int J Meth Psych Res 2004; 13: 93-121.

9 Wittchen H-U. Reliability and validity studies of the WHO Composite International Diagnostic Interview (CIDI): a critical review. J Psych Res 1994; 28: $57-84$.

10 Haro JM, Arbabzadeh-Bouchez S, Brugha TS, de Girolamo G, Guyer ME, Jin R, et al. Concordance of the Composite International Diagnostic Interview Version 3.0 (CIDI 3.0) with standardized clinical assessments in the WHO World Mental Health Surveys. Int J Meth Psych Res 2006; 15: 167-80.

11 American Psychiatric Association. Diagnostic and Statistical Manual of Mental Disorders (4th edn) (DSM-IV). APA, 1994.

12 Edwards WS, Winn DM, Kurlantzick V, Sheridan S, Berk ML, Retchin S, et al. Evaluation of National Health Interview Survey diagnostic reporting. Vital Health Stat 2 1994; 120: 1-116.

13 Kriegsman DM, Penninx BW, Van Eijk JT, Boeke AJ, Deeg DJ. Self-reports and general practitioner information on the presence of chronic diseases in community dwelling elderly. J Clin Epidemiol 1996; 49: 1407-17.

14 Kessler RC, Bergland P, Chiu WT, Demler O, Heeringa S, Hiripi E, et al. The US National Comorbidity Survey Replication (NCS-R): design and field procedures. Int J Methods Psychiatr Res 2004; 13: 69-92.

15 Kessler RC, Davis CG, Kendler KS. Childhood adversity and adult psychiatric disorder in the US National Comorbidity Survey. Psychol Med 1997; 27: 1101-19.

16 Golding JM. Sexual assault history and headache: five general population studies. J Nerv Ment Dis 1999; 187: 624-9. 
17 Walling MK, O'Hara MW, Reiter RC, Milburn AK, Lily G, Vincent SD. Abuse history and chronic pain in women. II. A multivariate analysis of abuse and psychological morbidity. Obstet Gynecol 1994; 84: 200-6.

18 Goodwin RD, Hoven CW, Murison R, Hotopf M. Association between childhood physical abuse and gastrointestinal disorders and migraine in adulthood. Am J Public Health 2003; 93: 1065-7.

19 Hardt J, Rutter M. Validity of adult retrospective reports of adverse childhood experiences: review of the evidence. J Child Psychol Psychiatry 2004; 45 260-73.

20 Peterlin BL, Ward T, Lidicker J, Levin M. A retrospective, comparative study on the frequency of abuse in migraine and chronic daily headache. Headache 2007; 47: 397-401.
21 Marlowe N. Stressful events, appraisal, coping and recurrent headache. J Clin Psychol 1998; 54: 247-56.

22 Passchier J, Schouten J, van der Donk J, van Romunde LK. The association of frequent headaches with personality and life events. Headache 1991; 31 $116-21$.

23 Romans S, Belaise C, Martin J, Morris E, Raffi A. Childhood abuse and later medical disorders in women. An epidemiological study. Psychother Psychosom 2002; 71: 141-50.

24 Eisenberger $\mathrm{NI}$, Lieberman MD, Williams KD. Does rejection hurt? An FMR study of social exclusion. Science 2003; 302: 290-2.

\section{Psychiatry} in the movies

\section{Look into my eyes}

\section{Peter Byrne}

When Freud abandoned hypnosis as a means of accessing the unconscious in 1909, he forgot to tell the motion picture industry. The evil mesmerist became the regular villain of one-reelers of early cinema. Hypnosis signified loss of control, its dark powers preying upon the innocent. It could be performed by 'foreigners' such as Dr Fu Manchu (in over 15 films), but most hypnotists were well-heeled professionals. Any dramatic impact of the unmasking of these charlatans was heightened by giving them trusted medical status. The crossover with psychiatry was established early: Dr Mabuse from Dr Mabuse the Gambler (1922, six remakes) is credited as cinema's first psychoanalyst.

Hypnotists stole and defrauded (The Magician, 1926), but 'taking advantage of the ladies' was their central activity, beginning with Under the Hypnotist's Influence (1897). Cabinet of Dr Caligari (Germany, 1919; pictured) was at once a horror show and Nazi metaphor - the director spiked it with verbatim quotes from Mein Kampf. The Nazis' detestation of both this film (banned as 'degenerate art') and psychiatry are documented elsewhere. In the decade ending 1939, three-quarters of screen hypnotists were either evil or mad, and mostly both. Though hypnosis helped Fred Astaire's love life and dancing in Carefree (1938), it framed an innocent woman in Whirlpool (1949) and facilitated low espionage in Masterplan (1955) and The Manchurian Candidate (1962).

Given this popularity and its appearance in children's animation, Jungle Book (1967) and Robin Hood (1973), hypnosis is probably the most (mis)represented of all 'psychiatric treatments' on film. It remains a popular narrative ploy, mostly in thrillers - Dead Again (1991) and the Bourne trilogy (2002-07) - where no smart money is bet on the integrity of the hypnotist. In Stir of Echoes (1999) and countless dissociative identity disorder films, hypnosis is the catalyst for libidinous mayhem. Movie hypnosis is seldom used for good (Inner Sanctum/Calling Dr Death 1943) - as with the television news maxim, 'if it bleeds, it leads'. Its power is ferocious - in Silence of the Lambs (1991), psychiatrist Hannibal Lecter is able to induce suicide in a detested fellow prisoner whom he cannot see, separated by several layers of bars and glass. Go figure.

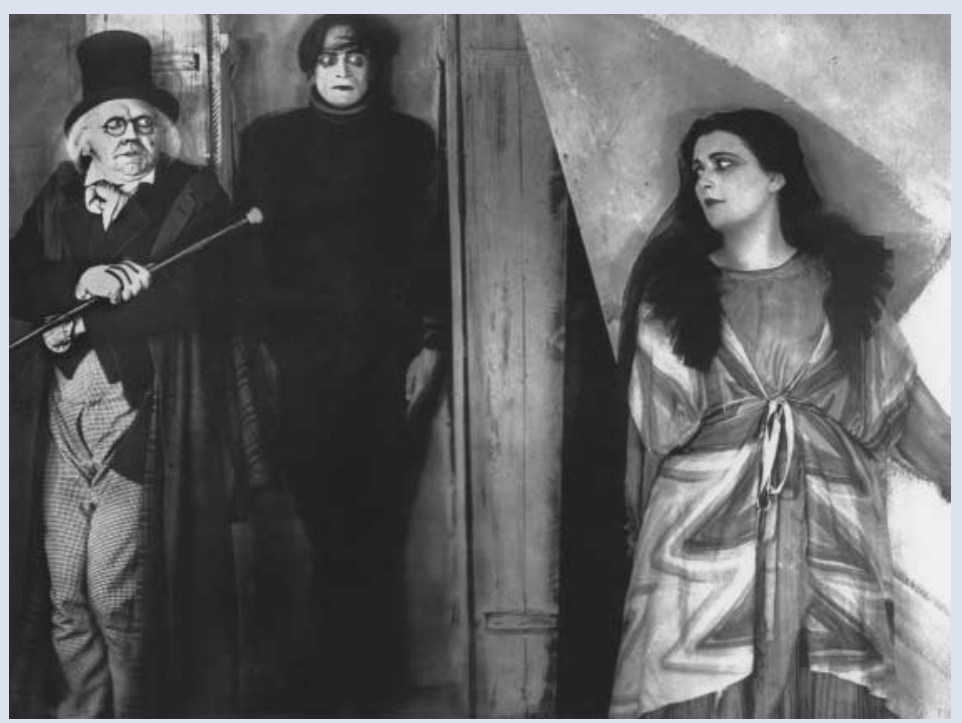

Still of evil Dr Caligari on left; somnambulist (centre) is Conrad Veidt, with Jane on right; image courtesy London Features International. 